\title{
NC Program Simulation with the Capability of Generating Alternative Process Plan for Flexible Manufacturing
}

\author{
Ferenc Erdélyi ${ }^{1}$ and Olivér Hornyák ${ }^{2}$ \\ ${ }^{I}$ PhD, Associate Professor \\ ${ }^{2}$ Assistant Professor \\ University of Miskolc, Faculty of Mechanical Engineering \\ Institute of Information Science, Department of Information Engineering
}

\begin{abstract}
This research effort focuses on improving the flexibility of production engineering for manufacturing industry by means of providing technological alternatives. A new generation of $\mathrm{NC}$ simulators required supporting the decision making of production engineering. In this paper a conception of NC simulator trying to fill this gap is given. This is a step forward realising Virtual Manufacturing.
\end{abstract}

Key words: CAPP, Robust NC Technology, Simulation, OOSE, Virtual Manufacturing

\section{INTRODUCTION}

In flexible manufacturing the applications of alternative and robust technology process plans play more and more important role in the practice of production management.

In a Computer Integrated Manufacturing (CIM) environment a Computer Aided Process Planning (CAPP) application is responsible for generating the process plans including NC part programs. Market demands requires these process plans to be optimised considering the actual business goals $[1,3]$.

Optimised process plan is a selected plan of some alternatives that meets all the valid constraints and guarantees the extreme (minimum or maximum) of an objective function preferred by the production management. For 
example, time, cost, volume produced or their weighed portfolio could be one of these goals.

The optimal control theory suggests the use of robust control that assures less sensitivity for the changing of process parameters or constraints, and for the change of the goal function, in more general sense.

In analogy to robust control we define the robust technology process plan. It represents that kind of planned technology process, which is not sensitive to technology parameters or constraints, and forms a group of alternatives (population) from which the production management can easily select the appropriate one in accordance with the actual demand $[4,6,7]$.

With CAPP (Computer Aided Process Planning) application tools, there are some new possibilities to make alternative process plans. These are as follows:

- Making alternative plans in the early period of product and process planning with concurrent engineering methods, in the premanufacturing phase. These serve for preparations to manage the changing environment during the life cycle of the manufacturing of the products.

- Making robust plans that exist in a single form but can easy be transformed accordingly to the different requirements of the actual production management goal. (This is an extended application of the processor - post processor principle proposed in APT (Automatically Programmed Tools) system at first 1955-58.

- Making plan-classes by means of integrated components that provide a possibility to generate plan object instances in the period of execution. (This is the principle of object oriented modelling methods.) The use of Group Technology (GT) and the intensity-based technology planning approach suggested by Hungarian researchers (Tóth \& Erdélyi, 1997) can be regarded as this kind of methods [7].

\section{GENERATING ALTERNATIVE NC PROGRAMS}

In most factories, programming of NC machine tools is supported by computer applications (Computer Aided NC Programming) traditionally named $\mathrm{CAD} / \mathrm{CAM}$ systems. These software applications support the geometric modelling of parts and tools as well as generation of tool paths resulting Cutter Location Data (CLD) files.

In case of conventional post-processing, the geometric model of the machining must remain unchanged; the generated NC program must fulfil the syntactical (formal) requirements of the available NC controller. The NC programming systems support this task by providing numerous post- 
processor components. The up-to-date $\mathrm{CAD} / \mathrm{CAM}$ systems offer the extension of technological capabilities. The volume and surface modelling, parametrical design, introduction of feature based geometrical modelling has become the base of creation of robust technological alternatives.

In the course of generating alternatives a certain number of Shop Floor Control (SFC) parameters can be used. The selection from these alternatives is an experience-based task. Some of these parameters are:

- accuracy parameters,

- tool parameters,

- tool path strategy,

- depth of cut in subprograms (in macros),

- technological intensity suggested by Tóth, 1988, (e.g.: in cutting operations: cutting rate or the rate of stock removal [8]),

- feed rate or cutting speed.

The comparison and the evaluation of the alternatives require some production performance indexes. Such indexes are the operation time and cost, the list of active tools, or the type of the machine (with the name of the postprocessor) etc.

There are two further significant techniques for making robust NC program alternatives that have possibility to create different performance indexes: These are as follows:

1. Creating alternatives in depth of cut structure or strategy of touring tool path.

2. Finding the optimal technological intensity in accordance with the different objective functions and constraints.

The first method has its advantage when using feature based programming macros. Fanuc, Siemens and other CNC controllers have had the capability of using this technique since the early ' $80 \mathrm{~s}$. This facility was introduced to support the Workshop Oriented Programming (WOP) and the user macro oriented manual programming. (e.g. the L95 macro family of Siemens SINUMERIC 810-840 which supports roughing cycle of turning operations). These macros have parameters that can be altered to create alternative part programs. The advantage of this method is that there is no need for re post-processing, and the alternatives are handled real-time by the executive tasks of the controller. However it has the disadvantage evaluating the objective function of the process posterior only.

The technological data (depth of cut, speed of cut, federate) can be involved to this task. New idea in this area is the optimisation of technological intensity that is applicable considering the objective functions and constrains coming from the production management in the early phase of process planning. 
Generation of multiple NC programs is a time consuming task. When the depth of cut does not appear as a parameter then it can be calculate by actual geometrical states and actual motion co-ordinates. When a spindle speed is given then the cutting speed doesn't appear explicitly, it is a function of cutting diameter (or the tool diameter in case of milling and grinding).

The NC programming applications allows the user to define these parameters interactively. When the NC program is manually generated, the macros supported by the controller can be parameterised properly. The same situation is in case of WOP when a special descriptive language of a certain controller can be used.

\section{EXTENDING THE NC SIMULATION}

The suitability of generated program variants must be examined. The most important criteria are the syntactical check and geometrical verification. Most of the NC programming systems includes simulator to verify the NC program with the use of graphical animation. However, these simulators do not offer information for MES (Manufacturing Execution System) except the operation time and some base data. It is noticeable that only the cutting time can be exactly calculated, the other times including tool changing times, rapid tool motion times, the set up, preparation and finishing times of a batch depends on the machine tool, the used tools, the alignment of tools etc.

The advanced flexible and adaptive Manufacturing Executions Systems requires the pre-estimation of further production parameters. Such as:

- operation cost,

- set up and operation times,

- cutting force, tool wear, tool cost,

- power of cutting process, consuming of energy, machine tool utilisation,

- prediction of dimensional accuracy, quality of surface, rate of waste product.

At present there are no simulators in the industrial practice, which can provide such services. The reason for this phenomenon can be found in the difficulties of modelling of machining operations.

Some of the indexes mentioned above are non-linear functions of the machining parameters. From Information Technology (IT) point of view these functions can be modelled using Artificial Intelligence (AI) techniques.

The research that has recently been in progress in the Department of Information Engineering at the University of Miskolc is targeted to the 
development of a new NC part program simulation tool for this advanced simulation. The main components of the simulator are as follows:

- NC part program code verification component

- Process simulator component, with

- Process definition component

- Process animation component

- Process analyser component

- Secondary Post Processor component

Figure 1. depicts the system architecture of the simulator with the most relevant interfaces to $\mathrm{NC}$ programming environment.

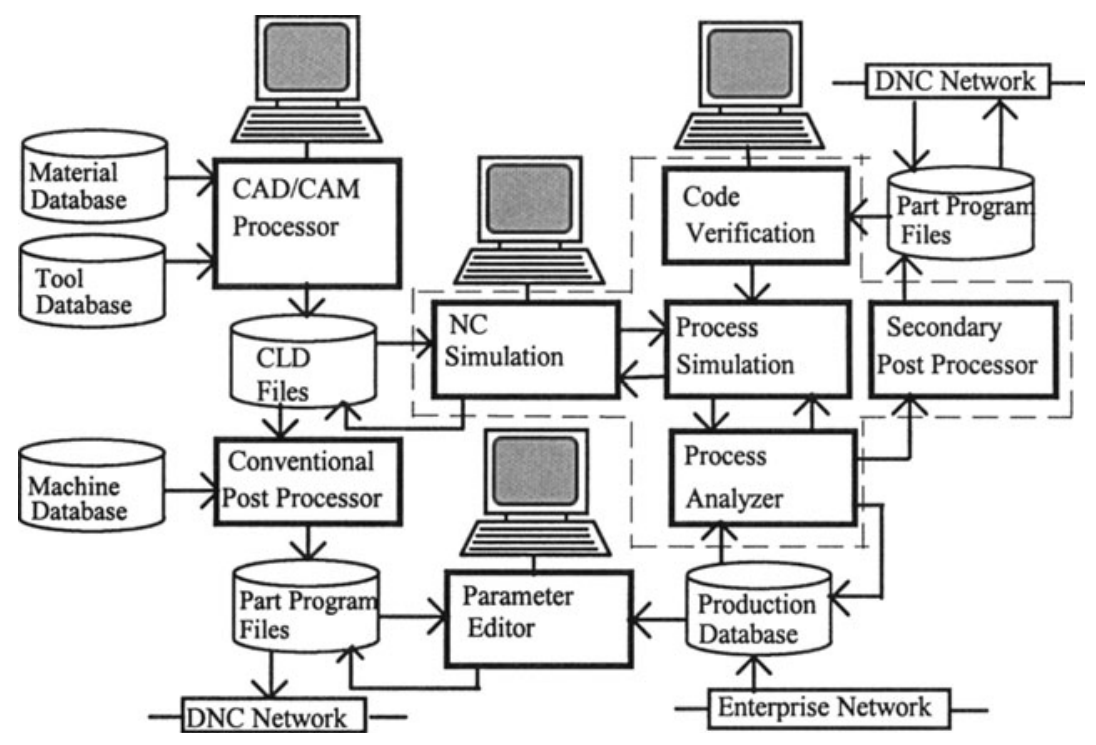

Figure 1. Components of extended NC simulator

\section{SOFTWARE ENGINEERING TOOLS FOR NC SIMULATION}

Object-oriented $(\mathrm{OO})$ programming has been revolutionizing software development and maintenance. When applied to simulation systems, $O O$ programming also provides an opportunity for developing new ways of thinking and modelling.

In this section some software engineering aspects of the existing application and the future work is given. 
During the Object Oriented Analysis and Design a set of classes has been worked-out for representing the geometric and technology entities of NC simulation. The use of $\mathrm{OO}$ technology makes it possible creating interfaces with these classes to other existing classes. It also supports software modules being under development or going to be developed in the future. The instances of these classes are the simulation objects involving all the information what an NC program can contain. Some aggregate management indexes of $\mathrm{NC}$ cutting operation (e.g. machining time, cost) can be evaluated as the time-integrated sum of certain attributes. Simulators in common use also provide graphic animation to check the NC program for semantic errors. Due to enclosing properties of objects each object is responsible for its representation during the animation. This also means that the attributes and member functions of an NC entity are suitable not only for modelling a real existing object but for supporting the software representation as well. This type of abstraction has a major effect on implementation and should be considered when mapping between objects and the process being modelled.

The process analyser of the NC simulator uses the management indexes coming from the process simulator. Most of them appear as non-linear functions of the cutting parameters. It is expedient to use AI methods for modelling those relationships. An Artificial Neural Network (ANN) module can be used to predict the cutting forces and tool life. Time related attributes could be directly predicted from the feed-rate and the tool path data of NC program. After computing these parameters, many other state variables can easy be estimated.

By means of the Secondary Post Processor component some new instances of the parameterised NC program class can be generated.

This introduces a new generation of $\mathrm{NC}$ simulation.

\section{CONCLUSIONS}

The paper discussed the technological trends of Computer Aided Process Planning. One of these possibilities is the use of process simulation over geometric simulation of NC part programs. Process simulator can support the production management in decision making, when goals of business change frequently. This is a step for realising Virtual Manufacturing in the field of NC turning. This paper and the background activity contribute to these aspects. 


\section{ACKNOWLEDGEMENTS}

The research summarized in the paper has been continued within the framework of Production Information Engineering Research Team (PIERT) established in the Department of Information Engineering and supported by the Hungarian Academy of Sciences. The research has also been supported by FKFP project entitled "Object Oriented Modelling of Manufacturing Processes" (Id.no.: 0275, headed by $F$. Erdélyi). The financial support of the research by the aforementioned sources is gratefully acknowledged.

\section{REFERENCES}

1. Chryssolouris, G. (1992): Manufacturing Systems, Theory and Practice. Springer, New York.

2. Chryssolouris, G., Mavrikos, D., Fragos, D. \& Karabatsan V. (2000): A Virtual Reality Based Experimentation Environment for the Verification of Human Related Factors in Assembly Process. Robotics and CIM. V.16. No.4. August: p. 267-277.

3. ElMaraghy, H.A. (1993): Evolution and Future Perspectives of CAPP. Annals of the CIRP, Vol. 42/2: p. 739-751.

4. Erdélyi, F \& Hornyák, O. (2001): Simulation tools for supporting robust process planning in the field of NC turning. Proceedings $3^{\text {rd }}$ Workshop on European Scientific and Industrial Collaboration, June: p. 27-29.

5. Hornyák, O. (1999): Object Oriented Software Engineering for Simulation of NC Machining Operations, X Workshop on Supervising and Diagnostics of Machining Systems. Innovate and Integrated Manufacturing, p. 96-102.

6. Phadke, M.S. (1989): Quality Engineering Using Robust Design. Prentice Hall, Englewood Cliffs.

7. Tóth, T. \& Erdélyi, F. (1997): The Role of Optimisation and Robustness in Planning and Control of Discrete Manufacturing Process. The 2nd CIRP World Congress in Intelligent Manufacturing, Budapest, Hungary, p. 205-210.

8. Tóth, T. (1988): Automatizált müszaki tervezés a gépgyártástechnológiában, Akadémiai doktori értekezés [Computer Aided Design and Planning in Production Engineering]. (in Hungarian), Budapest, DSc Dissertation, Hungarian Academy of Sciences. 